\title{
A Study to Detect Liver Enzyme Dysfunction among Patients on First Line Anti-Tubercular Drugs from RNTCP during the Course of Anti-TB Treatment
}

\author{
Rupam Kumar T. A. ${ }^{1}$, Samim Khan², Pronoy Sen ${ }^{3}$, Sourindranath Banerjee ${ }^{4}$
}

\begin{abstract}
${ }^{1}$ Department of Chest Medicine, Burdwan Medical College and Hospital, Bardhaman, West Bengal, India. ${ }^{2}$ Department of Chest Medicine, Burdwan Medical College and Hospital, Bardhaman, West Bengal, India. ${ }^{3}$ Department of Chest Medicine, Burdwan Medical College and Hospital, Bardhaman, West Bengal, India. ${ }^{4}$ Department of Chest Medicine, Burdwan Medical College and Hospital, Bardhaman, West Bengal, India.
\end{abstract}

\section{ABSTRACT}

\section{BACKGROUND}

Globally, an estimated 10.0 million people developed Tuberculosis in 2017. Side effects and toxicity of the first line anti-tubercular drugs were hepatotoxicity, skin rash, and joint pain. If hepatotoxicity develops on reintroduction of treatment with the same regimen, then treatment should be started with hepato-safe regimen. Majority of the reports have used an elevated Alanine Transaminase (ALT) or Aspartate Transaminase (AST) of 3 times upper limit of normal range (ULN) with symptoms attributable to liver injury or 5 times ULN of ALT or AST without symptoms to define hepatotoxicity. Due to paucity of studies regarding adaptive response, this study was conducted to find out the proportion of anti-tubercular drug (ATD) induced hepatitis during Anti-TB treatment and frequency of adaptive changes in Liver Enzymes during the course of anti TB treatment.

\section{METHODS}

116 patients who were diagnosed to have Pulmonary (PTB)/ Extrapulmonary (EPTB) tuberculosis at Outpatient \& In-Patients of Department of Chest Medicine, Burdwan Medical College \& Hospital, for eleven months after fulfilling the inclusion and exclusion criteria were included in the study. Treatment was given as per guidelines of Revised National TB Control Program.

\section{RESULTS}

In $83.3 \%$ patients only SGPT level was elevated, while in $71 \%$ SGOT was only elevated. Both SGPT and SGOT were elevated in $66.7 \%$ of cases. Only $1.8 \%$ cases were observed with elevated SGPT and SGOT on six occasions. Only $16.7 \%$ had no elevation in SGPT and $28.9 \%$ had no elevation in SGOT. Most of the patients had asymptomatic elevation of liver enzymes and didn't need any treatment interruption. $4.38 \%$ patients developed drug induced hepatitis and needed treatment interruption for about two weeks and all were reintroduced with the same regimen successfully.

\section{CONCLUSIONS}

Drug induced liver function abnormality is a common occurrence during the course of anti-TB treatment. Most patients show tolerance to anti-TB drugs and get adjusted after transient rise in liver enzymes. Concomitant use of hepatotoxic agent should be avoided as far as possible.

\section{KEY WORDS}

Hepatotoxicity, SGOT, SGPT, Adaptive Response, Tuberculosis
Corresponding Author: Dr. Sourindranath Banerjee, Burdwan Medical College and Hospital, Bardhaman-713103, West Bengal, India. E-mail:drsourin@gmail.com

DOI: $10.14260 /$ jemds/2020/141

Financial or Other Competing Interests: None.

How to Cite This Article:

Kumar RTA, Khan S, Sen P, et al. A study to detect liver enzyme dysfunction among patients on first line anti-tubercular drugs from RNTCP during the course of Anti-TB treatment. J. Evolution Med. Dent. Sci. 2020;9(09):645-650, $10.14260 /$ jemds/2020/141

Submission 18-12-2019, Peer Review 02-02-2020, Acceptance 11-02-2020, Published 02-03-2020.

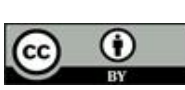




\section{BACKGROUND}

Human Tuberculosis, a known historical disease, as per genetic and archaeological data Mycobacterium tuberculosis complex (MTBC) may have co-existed with humans for 15,000 years.[1] It's aetiology was discovered by sir Robert Koch in March 24th 1882.[2] Globally, estimated 10.0 million people (range, 9.0-11.1 million) developed TB disease in 2017: 5.8 million men, 3.2 million women and 1.0 million children. ${ }^{[3]}$ Although with a running programme to control tuberculosis for almost more than 50 years TB continues to be India's one of the leading health hazard. Almost 480,000 persons die per year and more than 1,400 every day due to tuberculosis in India. Many cases are lost to follow up or inadequately treated in private sector. ${ }^{[4]}$

Side effects and toxicity of the first line anti-tubercular drugs (Rifampicin, Isoniazid, Pyrazinamide, Ethambutol and Streptomycin) are a hurdle to the physician and the patients for continuation of treatment.[5] The most severe side-effects leading to interruption of treatment were hepatotoxicity (11\%), skin rash (6\%), and joint pain (2\%).[5] Drug induced injury to liver with first line drugs is a serious challenge during the treatment as well as significant hazard while reintroduction of the same regimen.[6] Incidence of hepatotoxicity in Indian population is around $11.5 \%$, compared with $4.3 \%$ in western population, with mortality of $6-12 \%$ when continued even after the onset of symptoms. Some responsible factors for hepatotoxicity are older age, female population, poor nutritional status, high alcohol intake, existing liver disease, hepatitis B carriage, increased prevalence of viral hepatitis in developing countries, hypoalbuminemia and advanced tuberculosis, and inappropriate use of drugs.[7,8] Asymptomatic elevation of transaminases is common, around $20 \% \cdot{ }^{[9,10]}$ Clinical presentation of anti-tuberculosis drug induced hepatitis usually resembles acute viral hepatitis and resolves spontaneously following withdrawal of the anti-tuberculosis drugs. ${ }^{[9,10]}$ Many mechanisms were suggested for druginduced liver damage such as idiosyncratic damage, dosedependent toxicity, induction of hepatic enzymes, druginduced acute hepatitis and allergic reactions.[9,10] It takes around 16 weeks (range 6 weeks- 6 months) from treatment initiation to development of clinical symptoms.[10]

Though there are controversies regarding hepatotoxicity with alternate day regimen and daily regimen. Some studies are of opinion that there is no difference in hepatotoxicity incidences among daily and alternate day regimen.[11] Therefore, monitoring should be done after starting of Antituberculosis drugs every 2 weeks interval to get a chance to avoid undue disruption in treatment, fatal complications and better patient counseling.[12] Various studies have shown that Anti-TB drugs are common cause of hepatotoxicity worldwide. ${ }^{[13,14,15]}$ The incidence of anti-TB drug induced hepatotoxicity varies with the characteristics of the populations, drug regimens involved, upper limit used to define hepatotoxicity, monitoring and reporting pattern. Overall, hepatotoxicity due to anti-TB drugs has been reported in $5 \%-28 \%$ of people treated with anti-TB drugs. ${ }^{[14]}$ Many of these may not fit into a more recent international case definition of drug-induced liver injury (DILI). Majority of the reports have used an elevated alanine (ALT) or aspartate transaminase (AST) of 3 times upper limit of normal range
(ULN) with symptoms (abdominal pain, nausea, vomiting, unexplained fatigue or jaundice) attributable to liver injury or 5 times ULN of ALT or AST without symptoms to define hepatotoxicity.[16] Combination therapy develop transient asymptomatic elevation in liver enzymes, which comes to normal level with continuation of the drug.[17,18] The median interval from treatment initiation of drug to development of clinical symptoms is 16 weeks.[19,20]

Therefore, in a country like India where multi drug resistant tuberculosis cases are on a rise it will be beneficial not to withhold ATT without significant risk. Due to paucity of studies regarding adaptive response this study was conducted to find out proportion of anti-tubercular drug (ATD) induced hepatitis during Anti-TB treatment, frequency of adaptive changes in Liver Enzymes during the course of anti TB treatment.

\section{Objectives}

- To estimate proportion of anti-tubercular drug (ATD) induced hepatitis during Anti-TB treatment among patients with their previously normal liver function test (LFT) results.

- To find out frequency of adaptive changes in Liver Enzymes during the course of anti TB treatment.

- $\quad$ To find out average duration taken for deranged Liver enzymes to normalize.

- To find out any alternate regimen required in cases with hepatotoxicity.

- To find out number of episodes of deranged liver enzymes in due course of ATT.

\section{METHODS}

A prospective observational study after taking proper written consent from the patients was conducted in Outpatient Department (OPD) \& In-Patients of Department (IPD) of Burdwan Medical College, Department of Pulmonary Medicine after they were diagnosed with tuberculosis either clinically or microbiologically as pulmonary or extrapulmonary during the period of 11 months.

Base line data were collected such as history, detailed clinical examination, body mass index, residence, occupation, smoking and alcoholic status, sputum microscopy and CBNAAT, pleural fluid analysis (in cases of pleural effusion), lymph node fine needle aspiration for cytology and CBNAAT (in lymphadenopathy), Chest X-ray, and routine blood along with base line liver function test. All the patients were put on fixed dose combination (FDC) daily regimen with Isoniazid, Rifampicin, Pyrazinamide and Ethambutol as per RNTCP guidelines and according to body weight.

Blood samples were drawn for assessment of bilirubin, SGPT, SGOT and alkaline phosphatase (ALP) on follow-up at 2 weeks interval during the Intensive Phase (IP) and 1-month interval during Continuation Phase (CP). During each follow up visit detailed history and clinical check-ups were done and duly put down on preformed data sheet.

Patients were educated about the signs and symptoms of hepatitis and hepatotoxicity such as nausea, vomiting, abdominal pain and yellowish discoloration of skin and eyes. If any of the mentioned features observed then they were tested for hepatitis (viral) profile, prothrombin time, 
bilirubin, SGPT, SGOT and alkaline phosphatase test. Also, patients were tested for other organ involvement such, urea and creatinine. Normal range taken as for liver function tests were as follow bilirubin $<1.5 \mathrm{mg} / \mathrm{dL}$, SGPT $<40 \mathrm{IU} / \mathrm{L}$, SGOT $<40$ IU/L, ALP 40-120 IU/L, GGT <60 IU/L, Albumin >3 Gram\%. Hepatotoxicity was considered as per American Thoracic Society guidelines - as 1) rise in serum ALT above 5 times from baseline, 2) serum ALT above 3 times with symptoms like nausea, vomiting, pain abdomen and jaundice.

In cases with hepatitis patients were admitted in our indoor department and symptomatic treatment given. ATD were stopped for 2 weeks or until SGPT and SGOT comes down to less than 2 times the upper normal limit in cases with hepatitis. Re-introduction with ATD were done with same regimen in full doses after 2 weeks. Patients were closely observed for any further hepatitis. If symptomatic hepatitis develops or liver enzymes start raise alarmingly then patient were planned for shift the current regimen to hepato-safe regimen. Serial increase or decrease in liver function was recorded and patients were counseled not to take any hepatotoxic drugs or alcohol during the treatment period. Every patient's sputum samples were tested as per RNTCP guidelines. Those who were not responding to ATD regimens were further investigated for drug resistance. If any of the patients found to be a case of DRTB (Drug Resistance Tuberculosis) then he/she was excluded from the study.

\section{Statistical Analysis}

Statistical analysis was done by SPSS version 20. Categorical variables are expressed as Number of patients and percentage of patients and compared across the groups using Pearson's Chi Square test for Independence of Attributes/ Fisher's Exact Test as appropriate. Data does not follow normal distribution as tested by Kolmogorov-Smirnov and Shapiro-Wilk Tests and Hence Median is reported and NonParametric Tests used. Continuous variables are expressed as Mean, Median and Standard Deviation and compared over time using Wilcoxon Signed Ranks Test. Association between continuous variables are captured using Spearman's Rank Correlation Coefficient.

\section{RESULTS}

Out of 114 treated cases 5 patients developed hepatitis and were subjected to interruption in treatment, whereas rest of the patients continued treatment without any symptoms. Among the 5 patients 4 male and 1 female. 4 PTB and 1 EPTB. 2 patients developed hepatitis 4 weeks after treatment, 1 developed after 2 weeks, and other 2 patients developed after 4 months of treatment. 2 patients had BMI $<18.5 \mathrm{Kg} / \mathrm{m}^{2}$ and other were $>18.5 \mathrm{Kg} / \mathrm{m}^{2} .3$ patients were age below 40 years and 2 of the patients were above 40 years. All of them were newly diagnosed cases. Among the 5 cases 3 had SGPT and SGOT levels above 3 times but below 5 times and had symptoms like nausea vomiting and abdominal pain and jaundice. On the other hand, 2 cases had SGPT and SGOT above 5 times and they also presented with symptoms like jaundice, nausea and vomiting. Serum hepatitis virology markers were negative for all the 5 cases and their serum urea and creatinine levels were within normal limit.
Prothrombin time and INR was within normal range in all the hepatitis cases. All the case had raised serum bilirubin the time of hepatitis and were between $3 \mathrm{mg} / \mathrm{dL}$ and $5 \mathrm{mg} / \mathrm{dL}$. ATT was on hold for an average 2 (10 to 15 days) weeks for all the patients and same regimen of ATT continued. No second episode of symptomatic hepatitis developed later, although 2 patients had SGPT and SGOT above normal range but were below 2 times of upper normal limit. No other symptoms were noted in these cases of DILI. At the end of $6^{\text {th }}$ month all patients with ATT induced hepatitis had normal serum bilirubin, SGPT and SGOT level. Among the 114 patient's bilirubin levels were abnormal in $13.2 \%$ after $2^{\text {nd }}$ week, $7.9 \%$ after $4^{\text {th }}$ week, $6.1 \%$ after $6^{\text {th }}$ week, $5.3 \%$ after $8^{\text {th }}$ week, $3.5 \%$ after $3^{\text {rd }}$ month, $6.1 \%$ after $4^{\text {th }}$ month, $6.1 \%$ after $5^{\text {th }}$ month, but all patient had normal bilirubin after $6^{\text {th }}$ month. Mean, median and standard deviation in bilirubin levels during the treatment period were shown in table 2 . Statistically significant changes seen compared to bilirubin level at the start of treatment and $2^{\text {nd }}$ week [p-value $<0.001$, $4^{\text {th }}$ week [p-value 0.020$], 4^{\text {th }}$ month $\left[p\right.$-value 0.026 ] and $5^{\text {th }}$ month [p-value 0.016] [table 2].

\begin{tabular}{|c|c|c|c|}
\hline \multicolumn{2}{|c|}{ Characteristics } & No (n) & Percentage (\%) \\
\hline \multirow{6}{*}{ Age (Years) } & $11-20$ yrs. & 27 & \begin{tabular}{|l}
23.7 \\
\end{tabular} \\
\hline & $21-30$ yrs. & 39 & 34.2 \\
\hline & $31-40$ yrs. & 21 & 18.4 \\
\hline & $41-50$ yrs. & 4 & 3.5 \\
\hline & $51-60$ yrs. & 17 & 14.9 \\
\hline & $61-70$ yrs. & 6 & 5.3 \\
\hline \multirow{2}{*}{ Gender } & Male & 59 & 51.8 \\
\hline & Female & 55 & 48.2 \\
\hline \multirow{2}{*}{ Patient registered at } & IPD & 56 & 49.1 \\
\hline & OPD & 58 & 50.9 \\
\hline \multirow{2}{*}{ Address } & Rural & 73 & 64 \\
\hline & Urban & 41 & 36 \\
\hline \multirow{2}{*}{ Marital Status } & Married & 94 & 82.5 \\
\hline & Unmarried & 20 & 17.5 \\
\hline \multirow{2}{*}{ Smoking status } & Smoker & 43 & 37.7 \\
\hline & Non-smoker & 71 & 62.3 \\
\hline \multirow{2}{*}{ Alcohol Intake } & Yes & 42 & 36.8 \\
\hline & No & 72 & 63.2 \\
\hline \multirow[t]{2}{*}{ Sputum smear } & Positive & 41 & 36 \\
\hline & Negative & 73 & 74 \\
\hline \multirow{2}{*}{ Diagnosis } & Microbiologically & 77 & 67.5 \\
\hline & Clinically & 37 & 32.5 \\
\hline \multirow{2}{*}{ CBNAAT } & MTB Detected & 77 & 67.5 \\
\hline & MTB not Detected & 37 & 32.4 \\
\hline \multirow[t]{2}{*}{ Family/Contact H/O PTB } & Present & 64 & 56.1 \\
\hline & Absent & 50 & 43.9 \\
\hline \multirow{2}{*}{ Chest X-Ray } & Normal & 57 & 50 \\
\hline & Abnormal & 57 & 50 \\
\hline \multirow{2}{*}{ Case Type } & Newly Diagnosed & 94 & 82.5 \\
\hline & Previously Treated & 20 & 17.5 \\
\hline \multicolumn{4}{|c|}{ Table 1. Demographic Chart of TB Patients Included in the Study } \\
\hline
\end{tabular}

\begin{tabular}{|c|c|c|}
\hline Bilirubin (mg/dL) & Mean & Std. Deviation \\
\hline Bilirubin (mg/dL) - Day 0 & 0.95 & 0.27 \\
\hline Bilirubin (mg/dL) - 2nd Week & 1.13 & 0.52 \\
\hline Bilirubin (mg/dL) - Day 0 & 0.95 & 0.27 \\
\hline Bilirubin (mg/dL) - 4th Week & 1.06 & 0.49 \\
\hline Bilirubin (mg/dL) - Day 0 & 0.95 & 0.27 \\
\hline Bilirubin (mg/dL) - 6th Week & 1.01 & 0.37 \\
\hline Bilirubin (mg/dL) - Day 0 & 0.95 & 0.27 \\
\hline \multicolumn{2}{|c|}{ Wilcoxon Signed Ranks Test } \\
\hline
\end{tabular}

$39.5 \%(n=45)$ cases have elevated level of SGPT in only one follow up, while in $33.3 \%(n=38)$ SGOT was found to be elevated only once. Elevated level of and SGOT was observed in two follow-ups in $24.6 \%(n=28)$ and $25.4 \%(n=29)$ of cases. In three follow-ups $10.5 \%$ and $8.8 \%$ have elevated SGPT and SGOT respectively. In 7\% cases SGPT was elevated in four occasions while $0.9 \%(n=1)$ SGOT was raised in four 
follow-ups. Only $1.8 \%(n=2)$ cases were observed with elevated SGPT and SGOT in six occasions.

\begin{tabular}{|c|c|c|c|c|}
\hline & \multirow{2}{*}{ Mean } & $\begin{array}{c}\text { Std. } \\
\text { Deviation }\end{array}$ & \multicolumn{2}{|c|}{$\begin{array}{c}\text { of Confidence Interval } \\
\text { of the Difference }\end{array}$} \\
\cline { 4 - 5 } & Lower & Upper \\
\hline $\begin{array}{c}\text { Bilirubin (mg/dL) - Day 0 - } \\
\text { Bilirubin (mg/dL) - 2nd Week }\end{array}$ & -0.18 & 0.53 & -0.28 & -0.08 \\
\hline $\begin{array}{c}\text { Bilirubin (mg/dL) - Day 0 - } \\
\text { Bilirubin (mg/dL) - 4th Week }\end{array}$ & -0.12 & 0.52 & -0.21 & -0.02 \\
\hline $\begin{array}{c}\text { Bilirubin (mg/dL) - Day 0 - } \\
\text { Bilirubin (mg/dL) - 6th Week }\end{array}$ & -0.06 & 0.47 & -0.15 & 0.03 \\
\hline $\begin{array}{c}\text { Bilirubin (mg/dL) - Day 0 - } \\
\text { Bilirubin (mg/dL) - 8th Week }\end{array}$ & -0.05 & 0.51 & -0.14 & 0.05 \\
\hline $\begin{array}{c}\text { Bilirubin (mg/dL) - Day 0 - } \\
\text { Bilirubin (mg/dL) - 3rd month }\end{array}$ & -0.04 & 0.52 & -0.13 & 0.06 \\
\hline $\begin{array}{c}\text { Bilirubin (mg/dL) - Day 0 - } \\
\text { Bilirubin (mg/dL) - 4th month }\end{array}$ & -0.14 & 0.66 & -0.27 & -0.02 \\
\hline $\begin{array}{c}\text { Bilirubin (mg/dL) - Day 0 - } \\
\text { Bilirubin (mg/dL) - 5th month }\end{array}$ & -0.09 & 0.41 & -0.17 & -0.02 \\
\hline $\begin{array}{c}\text { Bilirubin (mg/dL) - Day 0 - } \\
\text { Bilirubin (mg/dL) - 6th month }\end{array}$ & -0.05 & 0.34 & -0.11 & 0.01 \\
\hline \multicolumn{3}{|c|}{ Table 3. Statistical Significance of Changes in Bilirubin Levels } \\
\hline
\end{tabular}

\begin{tabular}{|c|c|c|c|}
\hline \multicolumn{2}{|c|}{ Characteristic } & No (n) & Percentage (\%) \\
\hline \multirow{2}{*}{ Serum SGPT } & Elevated & 95 & 83.3 \\
\hline & Not elevated & 19 & 16.7 \\
\hline \multirow{2}{*}{ Serum SGOT } & Elevated & 81 & 71.1 \\
\hline & Not elevated & 33 & 28.9 \\
\hline \multirow{2}{*}{ Serum SGPT \& SGOT both } & Elevated & 76 & 66.7 \\
\hline & Not elevated & 38 & 33.3 \\
\hline \multirow{2}{*}{$\begin{array}{c}\text { Serum SGPT \& SGOT } \\
\text { elevated }\end{array}$} & $>5$ times & 2 & 1.75 \\
\hline & $>3$ times but $<5$ times & 3 & 2.63 \\
\hline \multirow{2}{*}{$\begin{array}{l}\text { Serum SGPT \& SGOT } \\
\text { elevated }>3 \text { times }\end{array}$} & Symptomatic & 5 & 4.38 \\
\hline & Asymptomatic & 0 & 0 \\
\hline \multirow{6}{*}{ SGPT Elevated in } & No Follow-up & 19 & 16.7 \\
\hline & 1 follow-up & 45 & 39.5 \\
\hline & 2 follow-ups & 28 & 24.6 \\
\hline & 3 follow-ups & 12 & 10.5 \\
\hline & 4 follow-ups & 8 & 7 \\
\hline & 6 follow-ups & 2 & 1.8 \\
\hline \multirow{7}{*}{ SGOT Elevated in } & No Follow-up & 33 & 28.9 \\
\hline & 1 follow-up & 38 & 33.3 \\
\hline & 2 follow-ups & 29 & 25.4 \\
\hline & 3 follow-ups & 10 & 8.8 \\
\hline & 4 follow-ups & 1 & 0.9 \\
\hline & 5 follow-ups & 1 & 0.9 \\
\hline & 6 follow-ups & 2 & 1.8 \\
\hline \multicolumn{4}{|c|}{ Table 4. Elevation of Liver Enzymes in Follow Up } \\
\hline
\end{tabular}

\section{DISCUSSION}

In our study, changing pattern of liver enzymes was observed and analysed. Drug induced Hepatitis is found to be the frequent adverse effect of ATT that causes an interruption of treatment. Retreatment started after symptomatic improvement and serum SGPT and SGOT comes down below twice the upper normal limit returned to normal levels. Confirmation of DILI was done by serum enzymes levels and by excluding other causes like viral hepatitis and by clinical improvement after drug withdrawal. Risk benefit effect ratio must be kept in mind while dealing with drugs adverse reaction and further continuation of treatment. In a developing country like India it is our priority not to defer the cost-effective treatment for manageable adverse reactions. To prevent undue occurrence of drug resistance holding Anti-TB drugs too long is a luxury that we can't afford. In the present study, transient hepatic function derangement was seen in patients initially more in the second week of treatment and the effect seems to fade of later subsequent follow up. All patients were closely monitored during treatment, counseling done to prevent use of any kind of hepatotoxic agents or alcohol. Those who developed hepatitis were also observed not report any kind of hepatic symptoms even after completion of treatment. And all patients completed their treatment successfully without further adverse reactions. So, from our study we can say that ATT can be reintroduced, even after hepatitis develop during treatment, safely after a gap and waiting for the patient to become asymptomatic with normalization of enzymes.[21,22]

In a study by Gulati et al. it was observed that most cases of hepatic enzyme elevations occur in intensive phase of ATT, in our study we have seen that most number patients have abnormal liver enzymes in second and fourth week after treatment.[23] As most anti-TB drugs are metabolized by the liver, therefore, it is the central to detoxification of INH, Rif, and PZA. So poor compliance in the initial phase of treatment is more likely. In the study by Vijayalakshmi et al drug induced hepatitis cases were reintroduced with hepato-safe regimen of ATT to complete the treatment, [24] but in our case, we stay with the same regimen and started with the full dose in all the 5 cases of hepatitis and didn't observed any further hepatitis in all the cases. A study with full dose reintroduction of all antitubercular drugs also had successful completion of ATT course comparable to other safer regimen.[25] Therefore, it can be said that though drug induced hepatitis can occur with the standard four drug regimen initially but on rechallenge same event may not happen. Incidence of drug induced hepatitis was $4.38 \%$ in our study which supporting the existing literature. As per the study by Surendra K Sharma et al ATT induced hepatitis was about $5 \%$ of all anti-TB treatment for Indian population and only $2 \%$ for western populations. ${ }^{[7]}$

Asymptomatic elevation liver enzymes are noted in various studies to be around 20\%.[26,27,28] But our study observes that this figure is much higher in our study population. Near about $76 \%$ patients in our study showing abnormal level of liver enzymes (Both SGPT and SGOT). Only $16.7 \%$ had no elevation in SGPT and $28.9 \%$ had no elevation in SGOT. So adaptive response to Anti-TB medications are much more common in our study population than previous studies. In previous studies it was found that average duration taken to get clinical symptoms and liver enzymes raised is variable from six weeks to six months.[29,30,31] In our study time taken to get enzyme elevation was 2 weeks up to 4 months. And hepatitis developed from 2 weeks up to 4 months after initiation of treatment.

\section{CONCLUSIONS}

Drug induced liver function abnormality is a common occurrence during the course of anti-TB treatment. Most patients show tolerance to anti-TB drugs and get adjusted after transient rise in liver enzymes. Some patients may develop serious hepatitis and need treatment interruption, but we should always try to stay with the present regimen and see whether reintroduction leads to any further derangement or hepatitis. Asymptomatic rise may be up to 3 times from the baseline value, but that does not need any intervention unless patients develop symptoms. Abdominal symptoms like pain, nausea, vomiting and jaundice should always be taken seriously and mark intervention by holding the ATT. Risk factors like, age, gender, smoking habits, alcohol intake, tuberculosis disease severity, must be studied 
further to have better understanding in relation to liver function changes. Concomitant use of hepatotoxic agent should be avoided as far as possible.

\section{REFERENCES}

[1] Hershkovitz I, Donoghue HD, Minnikin DE, et al. Tuberculosis origin: The Neolithic scenario. Tuberculosis (Edinb) 2015;95 (Suppl 1):S122-6.

[2] Sakula A. Robert Koch: centenary of the discovery of the tubercle bacillus, 1882. Thorax 1982;37 (4):246-51.

[3] Global Tuberculosis Report 2018. WHO - executive summary. 2018: p. 17.

[4] Revised National Tuberculosis Control Programme, National Strategic Plan for Tuberculosis Elimination 2017-2025: p. 5.

[5] Schaberg T, Rebhan K, Lode H. Risk factors for sideeffects of isoniazid, rifampin and pyrazinamide in patients hospitalized for pulmonary tuberculosis. European Respiratory Journal 1996;9 (10):2026-30.

[6] Kishore PV, Palaian S, Paudel R, et al. PR-drug induced hepatitis with anti-tubercular chemotherapy: challenges and difficulties in treatment. Kathmandu University Medical Journal (KUMJ) 2007;5 (2):256-60.

[7] Sharma SK, Balamurugan A, Saha PK, et al. Evaluation of clinical and immunogenetic risk factors for the development of hepatotoxicity during antituberculosis treatment. American Journal of Respiratory and Critical Care Med 2002;166 (7):916-9.

[8] Isa SE, Ebonyi AO, Shehu NY, et al. Antituberculosis drugs and hepatotoxicity among hospitalized patients in Jos, Nigeria. International Journal of Mycobacteriology 2016;5 (1):21-6.

[9] Sharma SK, Mohan A. Antituberculosis treatmentinduced hepatotoxicity: from bench to bedside. Chap 96. In: Gupta SB, edr, Medicine Update. Mumbai: The Association of Physicians of India 2005;15:479-84.

[10] Ramappa V, Aithal GP. Hepatotoxicity related to antituberculosis drugs: mechanisms and management. Journal of Clinical and Experimental Hepatology 2013;3 (1):37-49.

[11] Chang KC, Leung CC, Yew WW, et al. Standard antituberculosis treatment and hepatotoxicity: do dosing schedules matter? European Respiratory Journal 2007;29 (2):347-51.

[12] Yew WW, Leung CC. Antituberculosis drugs and hepatotoxicity. Respirology 2006;11 (6):699-707.

[13] Devarbhavi H, Dierkhising R, Kremers WK. et al. Singlecenter experience with drug-induced liver injury from India: causes, outcome, prognosis, and predictors of mortality. American Journal Gastroenterology 2010;105 (11):2396-404.

[14] Ostapowicz G, Fontana RJ, Schiodt FV, et al. Results of a prospective study of acute liver failure at 17 tertiary care centers in the United States. Ann Intern Med 2002;137 (12):947-54.
[15] Kumar R, Shalimar, Bhatia V, et al. Antituberculosis therapy induced acute liver failure: magnitude, profile, prognosis and predictors of outcome. Hepatology 2010;51(5):1665-74.

[16] Tostmann A, Boeree MJ, Aarnoutse RE, et al. Antituberculosis drug-induced hepatotoxicity: concise up-to-date review. J Gastroenterol Hepatol 2008;23 (2):192-202.

[17] Mitchell JR, Zimmerman HJ, Ishak KG, et al. Isoniazid liver injury: clinical spectrum, pathology and probable pathogenesis. Ann Intern Med 1976;84 (2):181-92.

[18] Scharer L, Smith JP. Serum transaminase elevations and other hepatic abnormalities in patients receiving isoniazid. Ann Intern Med 1969;71(6):1113-20.

[19] Kopanoff DE, Snider DE Jr, Caras GJ. Isoniazid-related hepatitis: a U.S. Public Health Service Cooperative Surveillance Study. Am Rev Respir Dis 1978;117 (6):991-1001.

[20] International Union against Tuberculosis Committee on Prophylaxis. Efficacy of various durations of isoniazid preventive therapy for tuberculosis: five years of followup in the IUAT trial. Bull World Health Organ 1982;60 (4):555-64.

[21] Lacroix C, Tranvouez JL, Hoang PT, et al. Pharmacokinetics of pyrazinamide and its metabolites in patients with hepatic cirrhotic insufficiency. Arzneimittelforschung 1990;40 (1):76-9.

[22] Singh J, Garg PK, Tandon RK. Hepatotoxicity due to antituberculosis therapy. Clinical profile and reintroduction of therapy. J Clin Gastroenterol 1996;22 (3):211-4.

[23] Dossing M, Wilcke JT, Askgaard DS, et al. Liver injury during antituberculosis treatment: an 11-year study. Tuber Lung Dis 1996;77 (4):335-40.

[24] Gulati K, Ray A, Vijayan VK. Assessment of protective role of polyherbal preparation, Livina, against antitubercular drug induced liver dysfunction. Indian J Exp Biol 2010;48 (3):318-22.

[25] Vijayalakshmi A, Thanmayi G, Jayakumari S. A prospective study on abnormal liver function test patterns in patients receiving anti-tuberculosis therapy. Asian J Pharm Clin Res 2016;9 (5):136-9.

[26] Sharma SK, Singla R, Sarda P, et al. Safety of 3 different reintroduction regimens of antituberculosis drugs after development of antituberculosis treatment-induced hepatotoxicity. Clin Infect Dis. 2010;50 (6):833-9.

[27] Girling DJ. The hepatic toxicity of antituberculosis regimens containing isoniazid, rifampicin and pyrazinamide. Tubercle 1978;59 (1):13-32.

[28] Ormerod LP, Horsfield N. Frequency and type of reactions to antituberculosis drugs: observations in routine treatment. Tuber Lung Dis 1996; 77 (1):37-42.

[29] Sharifzadeh M, Rasoulinejad M, Valipour F, et al. Evaluation of patient-related factors associated with causality, preventability, predictability and severity of hepatotoxicity during antituberculosis [correction of antituberclosis] treatment. Pharmacol Res 2005;51 (4):353-8. 
[30] Fountain FF, Tolley E, Chrisman CR, et al. Isoniazid hepatotoxicity associated with treatment of latent tuberculosis infection: a 7-year evaluation from a public health tuberculosis clinic. Chest 2005;128 (1):116-23.
[31] Kopanoff DE, Snider Jr DE, Caras GJ. Isoniazid-related hepatitis: a U.S. Public Health Service cooperative surveillance study. Am Rev Respir Dis. 1978; 117:9911001. 